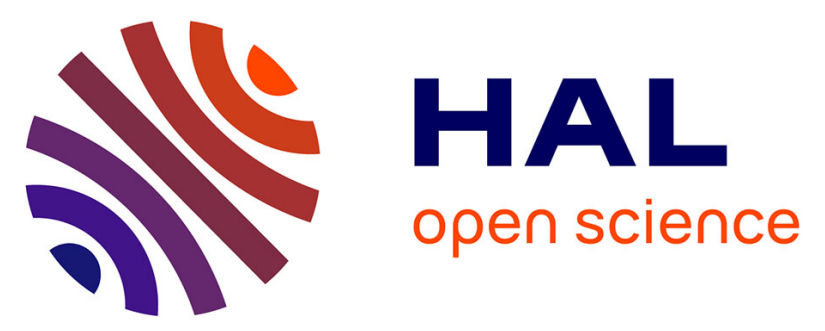

\title{
Confinement effect in PC/MXD6 multilayer films: Impact of the microlayered structure on water and gas barrier properties
}

Tiphaine Messin, Nadège Follain, Alain Guinault, Guillaume Miquelard-Garnier, Cyrille Sollogoub, Nicolas Delpouve, Valérie Gaucher, Stéphane Marais

\section{To cite this version:}

Tiphaine Messin, Nadège Follain, Alain Guinault, Guillaume Miquelard-Garnier, Cyrille Sollogoub, et al.. Confinement effect in PC/MXD6 multilayer films: Impact of the microlayered structure on water and gas barrier properties. Journal of Membrane Science, 2017, 525, pp.135-145. 10.1016/j.memsci.2016.10.039 . hal-01483691

\section{HAL Id: hal-01483691 \\ https://hal.science/hal-01483691}

Submitted on 6 Mar 2017

HAL is a multi-disciplinary open access archive for the deposit and dissemination of scientific research documents, whether they are published or not. The documents may come from teaching and research institutions in France or abroad, or from public or private research centers.
L'archive ouverte pluridisciplinaire HAL, est destinée au dépôt et à la diffusion de documents scientifiques de niveau recherche, publiés ou non, émanant des établissements d'enseignement et de recherche français ou étrangers, des laboratoires publics ou privés. 


\title{
Confinement effect in PC/MXD6 multilayer films: Impact of the microlayered structure on water and gas barrier properties
}

\author{
Tiphaine Messin $^{\mathrm{a}}$, Nadège Follain ${ }^{\mathrm{a}}$, Alain Guinault ${ }^{\mathrm{b}}$, Guillaume Miquelard-Garnier ${ }^{\mathrm{b}}$, \\ Cyrille Sollogoub $^{\mathrm{b}}$, Nicolas Delpouve ${ }^{\mathrm{c}}$, Valérie Gaucher ${ }^{\mathrm{d}}$, Stéphane Marais ${ }^{\mathrm{a}, *}$ \\ a Normandie Univ, UNIROUEN, INSA Rouen, CNRS, PBS, 76000 Rouen, France \\ b PIMM, Arts et Métiers ParisTech/CNRS/CNAM, 75013 Paris, France \\ c Normandie Univ, UNIROUEN, LECAP, 76000 Rouen, France \\ d Unité Matériaux et Transformations, UMR 8207 CNRS/Université Lille 1, 59655 Villeneuve d'Ascq, France
}

\section{A R T I C L E I N F O}

\section{Keywords:}

Multilayer

Permeability

Confined structure

Polycarbonate, poly(m-xylene adipamide)

Barrier properties

\begin{abstract}
A B S T R A C T
Films of PC and MXD6 were prepared via multilayer coextrusion. Films presenting stretched nodules/lamellas of MXD6 in the PC matrix, and films with quasi-continuous thin MXD6 layers alternating with PC layers were obtained.

The transport properties were specifically investigated from water and gas permeation kinetics, and the corresponding permeation parameters were determined. The confinement effect of MXD6 in the multilayer structure was highlighted by comparing the permeability predicted from the series model equation with the experimental data. Although the MXD6 layers were not homogeneous and continuous for all membranes, water and gas permeabilities of the PC/MXD6 multilayer film were largely reduced. Such improvement of barrier properties was related to the change of the MXD6 structure, considering that the confinement of the MXD6 layers induced by PC layers allowed to bring chain orientation and to reduce the chain segment mobility in the MXD6 amorphous constrained zones. In addition, in the case of a PC/MXD6 multilayer structure well defined with continuous layers and relatively homogeneous thicknesses, the degree of crystallinity was slightly increased.
\end{abstract}

\section{Introduction}

Polymer films find many applications in several fields such as packaging, medicine, cosmetic, coating, aeronautic or transport. Some key property requirements in these fields are good transparency, toughness, mechanical, thermal properties as well as barrier properties. To obtain such properties, blending or combining two (or more) polymers has been a classical top down approach, over many decades, to achieve polymer structures with properties larger than those of the individual components. Coextrusion process remains one of the most common industrial technique for elaborating polymer films consisting in a few (typically <10) stacked layers of different polymers with usually opposite technical characteristics (protective coating, filmforming properties, barrier properties, food contact, etc.), possibly combined with a tie layer or a compatibilizer [1,2].

Recently, it has been reported that an innovative technique of film processing, namely multilayer coextrusion, could be used to obtain materials with enhanced macroscopic properties [3]. Multilayer coextrusion is derived from classical coextrusion and its industrial potential has already been demonstrated by Dow which patented it close to 40 years ago $[4,5]$. With this process, starting from two (AB) or 3 layers (ABA) of polymers A and B, and by forcing the polymer flows through a series of Layer Multiplying Elements (LME), one can achieve films made of thousands of alternating A and B layers, in which all the layers have nanometric thicknesses (see Fig. 1) while the total thickness of the material remains those of a typical polymer film $(0.1-1 \mathrm{~mm})$. Baer's group in Case Western Reserve University widely used and developed this tool over the last 20 years and was able to produce materials with enhanced properties, in particular optical properties [6], mechanical properties $[7,8]$, gas barrier properties [9-11]. Those improvements were shown to arise from the multiplication of the interfaces and/or the confinement, induced by the process (named 'forced-assembly').

In particular, for semi-crystalline polymers, this innovative technique has been recognized as an effective way to induce one-dimensional confined crystallization of polymers [12]: when the polymer layer thickness decreases, the crystalline morphology is gradually altered from a three-dimensional spherulitic morphology into one-dimensional crystalline lamellae. For example, in the case of poly(ethylene oxide)

\footnotetext{
* Corresponding author.

E-mail address: stephane.marais@univ-rouen.fr (S. Marais).
} 


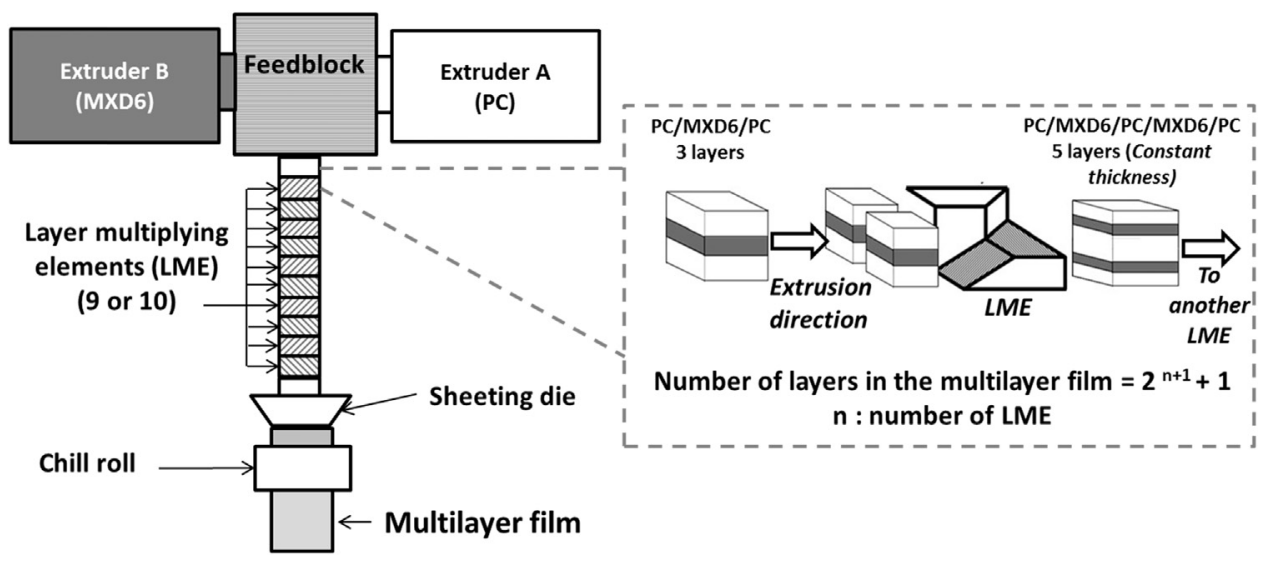

Fig. 1. Schematic principle of the coextrusion process with a multiplying elements device.

(PEO) [13] or poly( $\varepsilon$-caprolactone) (PCL) [14], confined with an amorphous polymer (typically PS), an in-plane orientation of crystalline lamellae of PEO or PCL have been obtained. In those cases, a significant reduce of gas permeability has been measured (more than two orders of magnitude reduction). For other polymers, it happens that confinement can favor other crystal morphologies or orientation $[12,15]$. In such cases, permeability is not improved (or even may be worsened) but post-processing procedures, thermal annealing possibly combined with (biaxial) stretching, may allow to provide the desired crystal morphologies.

Geometric confinement may also have an effect on the amorphous phase, inducing chain orientation or modifying the amorphous phase dynamics. For example, molecular mobility changes have been observed in PC/PMMA multilayered films [16], as the thickness of each component became thinner than $125 \mathrm{~nm}$ : PC exhibited a drastic decrease in cooperativity volume (measured with TM-DSC) whereas slight modifications were observed for PMMA.

Poly(m-xylene adipamide) (MXD6) is an aromatic polyamide with excellent barrier properties due to its benzene ring. It was first synthesized in the 50 's, then produced industrially in the 80 's by Mitsubishi using direct polycondensation [17], and is classically blended with PET for food packaging applications $[18,19]$. MXD6, that crystallizes slowly [20], is usually amorphous when extruded and needs post-processing treatment, such as thermal annealing or hot drawing, to induce crystallization and thus improve its gas transport properties. MXD6 also has ability to crystallize in contact with water, which will impact its barrier properties over time and/or exposure with water [21-23]. To date no attempt of using multilayer coextrusion to achieve thin layers of MXD6 and study the impact of this confinement on the barrier properties has been published in the literature. As it was exposed before, geometric confinement may have effect on the crystalline phase as well as on the amorphous one, and thus impact barrier properties.

In some cases it has been observed that this process is subject to instabilities which give rises to rupture of the layers [24,25], especially with complex polymers like MXD6. However, if the structures created are still under the form of elongated lamellas, they may still be of interest for gas barrier applications [26].

In this context, we prepared in this study films with alternating polycarbonate (PC) and MXD6 layers, composed of numerous thin layers of MXD6. PC was chosen since it is amorphous and has a high glass transition temperature which should favor the confinement of the MXD6 and the understanding of the resulting phenomena. Quasicontinuous layers as well as elongated lamellae were obtained, depending on the number of LME used. A structural characterization was conducted on the different films to evaluate the influence of the resulting multilayer structure on crystallinity, crystal orientation and lamella size. A comparison was done with films obtained by the classical blending of the two polymers. Again, for the sake of comparison, monolayer films of MXD6 and of PC were also extruded to be used as references in order to highlight the properties of the multilayered structures and the corresponding changes. Moreover, for a better insight of the confinement effect induced by amorphous polymer layers, multilayer films containing only the amorphous polymer, noted PC/PC multilayer film, and only the semi-crystalline polymer, noted MXD6/MXD6 multilayer film, were prepared. Transport properties of gases and water were analyzed and compared to the PC monolayer and MXD6 monolayer films. The structuremorphology-property relationships will be discussed in the present study. In particular, a deep analysis of the transport properties, on the basis of thermodynamic and kinetic aspects, has been performed by testing four molecular probes $\left(\mathrm{N}_{2}, \mathrm{O}_{2}, \mathrm{CO}_{2}, \mathrm{H}_{2} \mathrm{O}\right)$, differing in size and interaction capacity. From permeation kinetics and the resulting permeation parameters, the structural effects within the multilayer films were clearly correlated to barrier properties.

\section{Experimental}

\subsection{Materials}

Amorphous polycarbonate, referenced as LEXAN 121R $\left(\mathrm{Tg}=145^{\circ} \mathrm{C}\right.$ ) was supplied by SABIC (Saudi Arabia). Semi-crystalline aromatic poly(m-xylene adipamide), MXD6 grade $6007\left(\mathrm{Tg}=85^{\circ} \mathrm{C}\right)$ was obtained from Mitsubishi Gas Chemical. They were chosen to have viscosity ratio as close as possible to 1 . At a processing temperature of $260{ }^{\circ} \mathrm{C}$ and at shear rates equivalent of those imposed in the extruders $\left(1-100 \mathrm{~s}^{-1}\right)$, the viscosities of PC and of MXD6 polymers were measured equal to 822 and $1690 \mathrm{~Pa} \mathrm{~s}$, respectively, which induces a viscosity ratio of 2 . The PC and MXD6 pellets were dried at $120^{\circ} \mathrm{C}$ overnight before processing. The residual moisture content was measured and found to be less than $0.02 \%$ for PC and $0.1 \%$ for MXD6.

\subsection{Films preparation}

The layer-multiplying coextrusion process consists of two singlescrew Scamex extruders (France) combined in a classical A/B/A coextrusion feed block, to obtain a 3-layers polymer flow, and equipped with a layer-multiplying elements-device placed at the end of the feed block (Fig. 1). The device aims to cut vertically the 3-layers flow into two parts, which are thereafter superposed and compressed in order to obtain a 5-layers flow. The number of layers was evenly calculated with the following Eq. (1) [27]:

Number of layers $N=2^{(n+1)}+1$

With $n$ is the number of multiplying elements. 


\subsubsection{Elaboration of monolayer films: $P C$ monolayer and MXD6 monolayer films}

The two monolayer films were directly prepared from a classical single-screw extruder ( $20 \mathrm{~mm}$ diameter Scamex extruders with a barrel of length-to-diameter ratio of 20), without feed block and multiplying elements-device, with a temperature profile of $310 / 280 / 260 / 260{ }^{\circ} \mathrm{C}$ from the hopper to the die and a screw speed of $40 \mathrm{rpm}$. The chill-roll temperature was adjusted to $130{ }^{\circ} \mathrm{C}$ and $90{ }^{\circ} \mathrm{C}$ for PC and MXD6, respectively. The final thicknesses of the films were respectively $200 \mu \mathrm{m}$ for PC and $260 \mu \mathrm{m}$ for MXD6 films.

\subsubsection{Elaboration of multilayer films made of one polymer: $P C / P C$ multilayer and MXD6/MXD6 multilayer films}

Multilayer films at a 75/25 weight ratio were coextruded by using a series of 10 multiplying elements, to theoretically obtain 2049 layersfilm, with a total polymer flow fixed at $1200 \mathrm{~g} / \mathrm{h}$ to prevent thermal polymer degradation by adjusting the residence time. The PC/PC film was prepared from two single-screw extruders (extruder 1: Scamex, $20 \mathrm{~mm}$ diameter, $25 \mathrm{rpm}$ with a temperature profile of 330/300/260/ $260{ }^{\circ} \mathrm{C}$; extruder 2: Scamex, speed at $22 \mathrm{rpm}$ with a temperature profile of $330 / 300^{\circ} \mathrm{C}$ ), with the multiplying elements-device at $270{ }^{\circ} \mathrm{C}$. The films were then spread through a flat die (width of $100 \mathrm{~mm}$ and thickness of $1 \mathrm{~mm}$ ) at $260^{\circ} \mathrm{C}$ and onto the chill roll at $130^{\circ} \mathrm{C}$. The final thickness was $200 \mu \mathrm{m}$. For the MXD6/MXD6 film, the films were coextruded (extruder 1:19 rpm with a temperature profile of 310/280/ $260 / 260{ }^{\circ} \mathrm{C}$; extruder 2 : speed at $31 \mathrm{rpm}$ with a temperature profile of $310 / 270{ }^{\circ} \mathrm{C}$ ), and were then spread through the flat die (width of $100 \mathrm{~mm}$ and thickness of $1 \mathrm{~mm}$ ) at $260^{\circ} \mathrm{C}$ and onto the chill roll at $90{ }^{\circ} \mathrm{C}$ to allow relaxation of MXD6. The final thickness was measured equal to $200 \mu \mathrm{m}$.

\subsubsection{Elaboration of multilayer films made of the two polymers: $P C /$ MXD6 multilayer film}

Two series of PC/MXD6 films were prepared with two specific processing conditions with the aim of adjusting the composition ratio and the number of layers within the films.

For the first series at a 75/25 ratio, noted PC/MXD6-1 film, the multilayer film was coextruded (extruder 1: Scamex, $20 \mathrm{~mm}$ diameter, speed at $48 \mathrm{rpm}$ with a temperature profile of $310 / 280 / 260 / 260^{\circ} \mathrm{C}$; extruder 2: Scamex, $20 \mathrm{~mm}$ diameter, speed at $60 \mathrm{rpm}$ with a temperature profile of $310 / 270{ }^{\circ} \mathrm{C}$ ) with a total polymer flow fixed at $2400 \mathrm{~g} / \mathrm{h}$, to prevent PC bubbles initiated by atmosphere humidity, by using a 10 multiplying elements-device (to form theoretically 2049 layers within the film) at $265{ }^{\circ} \mathrm{C}$. The melt flow was spread through the flat die at $260{ }^{\circ} \mathrm{C}$ and then onto the chill roll at $130{ }^{\circ} \mathrm{C}$.

For the second series at a 80/20 ratio, noted PC/MXD6-2 film, the coextrusion process (extruder 1: Scamex, speed at $26 \mathrm{rpm}$ with a $310 /$ $280 / 260 / 260^{\circ} \mathrm{C}$ profile; extruder 2 : speed at $31 \mathrm{rpm}$ with a $310 /$ $260{ }^{\circ} \mathrm{C}$ profile) was performed using a 9 multiplying elements-device (giving film with 1025 layers) at $245^{\circ} \mathrm{C}$. Indeed, the decision to reduce the number of mixing elements was taken since layer break-up was observed when using 10 multiplying elements. The melt flow was spread through the flat die at $240^{\circ} \mathrm{C}$ and then onto the chill roll at $130{ }^{\circ} \mathrm{C}$.

The multilayer films with an average thickness of $200 \mu \mathrm{m}$ were selected and were stored at room temperature in desiccators (under vacuum with $\mathrm{P}_{2} \mathrm{O}_{5}$ ) for further characterizations.

\subsection{Morphological characterization}

Films were observed with an optical transmission microscope (Axio Imager.a2m, Zeiss) under polarized light to differentiate the two phases. The grey phase corresponds to PC polymer and the dark phase to MXD6 polymer. Samples were prepared by using a microtome (Leica RM2255 microtome) to obtain a $10-20 \mu \mathrm{m}$ thickness sample for observation.
Wide Angle X-ray Scattering (WAXS) experiments were performed using a Genix microsource X-ray generator operated at $50 \mathrm{kV}$ and $1 \mathrm{~mA}$. The $\mathrm{Cu}-\mathrm{Ka}$ radiation $(\lambda=1.54 \AA)$ was collimated with a FOX2D mirror and two pairs of Scatterless slits from Xenocs. The 2D-patterns were recorded on a CCD camera from Photonic Science. All the X-ray patterns were corrected from background scattering and normalized using the transmission factor, defined as the ratio between the transmitted and the incident intensities measured with WAXS data acquisition. Radial intensity profiles $I(2 \theta)$ are obtained by azimuthal integration of the 2D-patterns using FIT2D software.

\subsection{Thermal properties (TGA, DSC)}

Thermal properties of the neat films and the multilayer films were analyzed by thermogravimetric analyses (TGA), by classical differential scanning calorimetry (DSC) and by modulated-temperature DSC (MTDSC).

TGA analyses were performed with a Q500 TGA from TA Instrument, with a heating rate of $10^{\circ} \mathrm{C} / \mathrm{min}$ from 30 to $600{ }^{\circ} \mathrm{C}$ under nitrogen. The degradation temperature $\left(\mathrm{T}_{\mathrm{deg}}\right)$ was determined for a loss of $5 \%$ by mass of the sample.

DSC experiments were performed on around 6-7 mg of sample with a Discovery series Differential Scanning Calorimeter from TA Instruments at a heating/cooling rate of $10{ }^{\circ} \mathrm{C} / \mathrm{min}$ from -10 to $300{ }^{\circ} \mathrm{C}$ in aluminum pan, after temperature calibration using indium standard. The degree of crystallinity was calculated by:

$X c=\frac{\Delta H m-\Delta H c}{\Delta H_{m}^{0}} * 100$

Where $\Delta H m$ is the enthalpy of melting, $\Delta H c$ is the enthalpy of crystallization and $\Delta H_{m}^{0}$ is the theoretical enthalpy of melting of the $100 \%$ crystalline polymer. For the MXD6, $\Delta H_{m}^{0}$ is equal to $175 \mathrm{~J} / \mathrm{g}$ [21]. The degree of crystallinity was determined from the first heating step because the value is supposed to be the crystallinity of the films when analyzing by permeation measurements.

MT-DSC experiments were performed with a DSC Q2000 from TA Instruments, in "Heat-Only" mode, from 0 to $270{ }^{\circ} \mathrm{C}\left( \pm 0.318{ }^{\circ} \mathrm{C}\right.$ for the oscillation amplitude, $60 \mathrm{~s}$ for the oscillation period and $2{ }^{\circ} \mathrm{C} \mathrm{min}{ }^{-1}$ as heating rate).

\subsection{Mechanical properties}

Uniaxial tensile tests were performed at room temperature on an Instron 5543 traction machine with a $500 \mathrm{~N}$ sensor. The samples were dumbbell-shaped with dimensions of 30 in length $\times 4 \mathrm{~mm}$ in width under $0.20 \mathrm{~mm}$ of thickness. A crosshead speed was fixed at $5 \mathrm{~mm} / \mathrm{min}$ in order to compare with values of MXD6 film already published in a separate paper [28]. The stress-strain curves were plotted and the tensile modulus, also noted Young's modulus was deduced from the low strain region. At least ten specimens per film were tested and the mean values were reported for ultimate mechanical properties, i.e. nominal elongation and nominal strength.

\subsection{Transport properties}

\subsubsection{Gas permeation}

Gas permeation measurements were performed at $25{ }^{\circ} \mathrm{C}$ with a labbuilt apparatus [29]. The film was placed in the permeation cell composed of the upstream and the downstream parts, in which vacuum was applied for $15 \mathrm{~h}$. Then, the upstream part compartment was fed with gas $\left(\mathrm{N}_{2}, \mathrm{O}_{2}\right.$, or $\mathrm{CO}_{2}$ at a pressure of 4 bars), while a pressure sensor monitored the increasing of pressure in the downstream part. This barometric method called "time-lag" method gives access to permeability coefficient $P$, expressed in Barrer (1 Barrer $=10^{-10} \mathrm{~cm}_{\text {(STP) }}^{3} \mathrm{~cm} \mathrm{~cm}^{-2} \mathrm{~s}^{-1} \mathrm{cmHg}^{-1}$ ), by measuring the quan- 
tity of diffusing molecules which passed through the film as a function of time, according to:

$P=\frac{J s t^{*} L}{\Delta p}$

With $J s t$ is the stationary flux, $L$ is the film's thickness and $\Delta p$ is the difference of pressure between the upstream and the downstream parts of the permeation cell.

The stationary flux $J s t$ is calculated from the slop $\alpha$ of the kinetic curve at long time:

$J s t=\frac{\alpha^{*} V}{A^{*} R^{*} T}$

With $V$ is the volume of the downstream compartment, $R$ is the ideal gas constant, $A$ is the surface of film exposed to gas and $T$ is the experimental temperature.

For the sake of comparison, a predicted permeability coefficient was calculated from two different approaches. One on the basis of the Maxwell model [30-32] taking into account a two-phase mixtures with one continuous phase (PC) and a disperse phase (MXD6) as follows:

$P_{\text {Film }}=P_{\mathrm{PC}} * \frac{1+2 \varphi_{\mathrm{MXD} 6}(\lambda-1) /(\lambda+2)}{1-\varphi_{\mathrm{MXD} 6}(\lambda-1) /(\lambda+2)}$

where $P_{\text {Film }}$ is the permeability coefficient of the film of two phase mixture, $P \mathrm{PC}$ is the permeability of the continuous phase (PC), $\varphi_{\mathrm{MXD} 6}$ is the volume fraction of the dispersed phase (MXD6) and $\lambda$ is the relative permeability of the dispersed phase into the continuous phase $\left(\lambda=P_{\mathrm{MXD} 6} / P_{\mathrm{PC}}\right)$.

And the other one, corresponding to the ideal case where the two phase mixture is composed of infinite lamellae and that can be defined as a multilayer structure for which each layer is a lamella, the wellknown series model [11,33-35] can be considered as follows:

$\frac{1}{P_{\text {Film }}}=\frac{\varphi_{\mathrm{MXD} 6}}{P_{\mathrm{MXD} 6}}+\frac{\varphi_{\mathrm{PC}}}{P_{\mathrm{PC}}}$

With $\varphi i$ is the volume fraction and $P i$ is the permeability coefficient, the index i corresponds to polymers, PC and MXD6.

\subsubsection{Water permeation}

Water permeation measurements were performed at $25{ }^{\circ} \mathrm{C}$ with a lab-made apparatus composed of a permeation cell in which the film separates the upside from the downside compartments. The two parts of the permeation cell were swept with dry nitrogen until a low constant dew point $\left(\approx-70{ }^{\circ} \mathrm{C}\right)$, monitored by a chilled mirror hygrometer (Elcowa ${ }^{\circledR}$, France, General Eastern Instruments), is reached. Then, the upstream compartment was filled with liquid water (milli Q) and the downstream compartment was continuously swept by a nitrogen flux. The permeation flux of water passing through the film was measured by following the variation of the dew-point temperature as a function of time. At the stationary state, the permeation flux $J_{s t}$ is directly proportional to the permeability coefficient $\mathrm{P}$ (expressed in Barrer) according to:

$P=\frac{J s t^{*} L}{\Delta a}$

With $J_{s t}$ is the stationary flux and $\Delta a$ is the difference of water activity between the upstream and the downstream compartments of the permeation cell ( $\Delta a=1$ in our case).

\section{Results and discussion}

It is generally accepted that permeation properties of polymer membranes are directly dependent on the structure of the polymer assembly resulting from the processing used and also on the ability of polymer chains to crystallize into semi-crystalline phase and/or to be oriented. Recently, Wang et al. [10] have discovered a new crystalline morphology, resulting from constrained two-dimensional polymer crystallization and induced by forced assembly of a specific coextrusion process, which presents outstanding gas permeation properties superior, than those expected from the bulk polymers, due to the specific lamellar crystal orientation within the layered film. In the present work, it was really interesting to see how the confinement of MXD6 intended within the PC/MXD6 films could change the structure of the film and the resulting transport properties. Therefore, to evidence the properties of the confined MXD6 layers within the PC/MXD6 films, DSC and permeation measurements were performed on the PC monolayer and MXD6 monolayer films, also called the neat films, to serve as reference and likewise on PC/PC and MXD6/MXD6 multilayer films to evaluate the level of improvement in barrier properties.

\subsection{Structure and morphology}

The Polarized Optical microscopy (POM) observations were carried out to show the existence of a continuous alternating layer structure within the multilayered films and to highlight eventually a difference of crystallinity of the layers with the film thickness by means of polarized light. For the MXD6/MXD6 film, no apparent layered structure was observed in the cross-section. However, even if the structure of this film seems homogeneous in the entire thickness, it is possible that the confined layers of MXD6 (at least 1000 MXD6 confined layers with 10 multiplying elements) in such multilayer MXD6 structure, can lead to changes in permeation properties, compared to the neat MXD6 film. Concerning the PC/PC multilayer film, it was not possible to clearly observe the multilayer structure, because of its amorphous state. However, at a macroscopic scale, this multilayer film seems to be homogeneous.

From the POM image shown in Fig. 2, the PC/MXD6-1 film can be considered as a membrane made of a polymer blend with more or less stretched nodules of MXD6.

For the PC/MXD6-2 film, the layer continuity is evidenced in the middle of the film (except for the film edges). In addition, the layers seem to be thin but with some irregularities, in particular in thickness. The measured layer thickness of the film imaged varies from about $0.5-5 \mu \mathrm{m}$ for MXD6 (in black) and PC (in grey) layers, respectively, while it was expected for theoretical thicknesses equal to $0.08 \mu \mathrm{m}$ and $0.32 \mu \mathrm{m}$ respectively for MXD6 and PC. It is interesting to see that the quality of the structure of the PC/MXD6 multilayer film is strongly dependent on the process conditions which are slightly changed. With a 9 multiplying elements-device, a continuous layer structure is obtained, while with the use of a 10 multiplying elements-device the layers are disrupted.

Wide Angle X-ray Scattering (WAXS) measurements were performed to detect changes in the crystalline structure of the different multilayer films, compared with monolayer films. Concerning the PC monolayer and PC/PC multilayer films, from the WAXS diffractograms (Fig. 3) and also as expected, an amorphous halo was observed, reflecting an amorphous structure. The same observation was made for the MXD6 in monolayer and multilayer forms due to a very low crystallinity rate. Indeed, it is worth noting that the limit of detection being around $5 \%$ to detect a crystalline structure from XRD data; it seems appropriate that no crystalline structure is observed. Concerning the two PC/MXD6 multilayers films, an amorphous halo was also obtained, similar to those observed for the neat monolayer films, meaning that no change in the MXD6 crystalline structure was generated by the use of the layer-multiplying coextrusion process, certainly due to the very low crystallinity rate of MXD6.

\subsection{Thermal and mechanical properties}

DSC measurements were performed to analyze the thermal behavior of the neat and the multilayer films and also to determine the degree of crystallinity. The DSC curves from the first heat are plotted in 

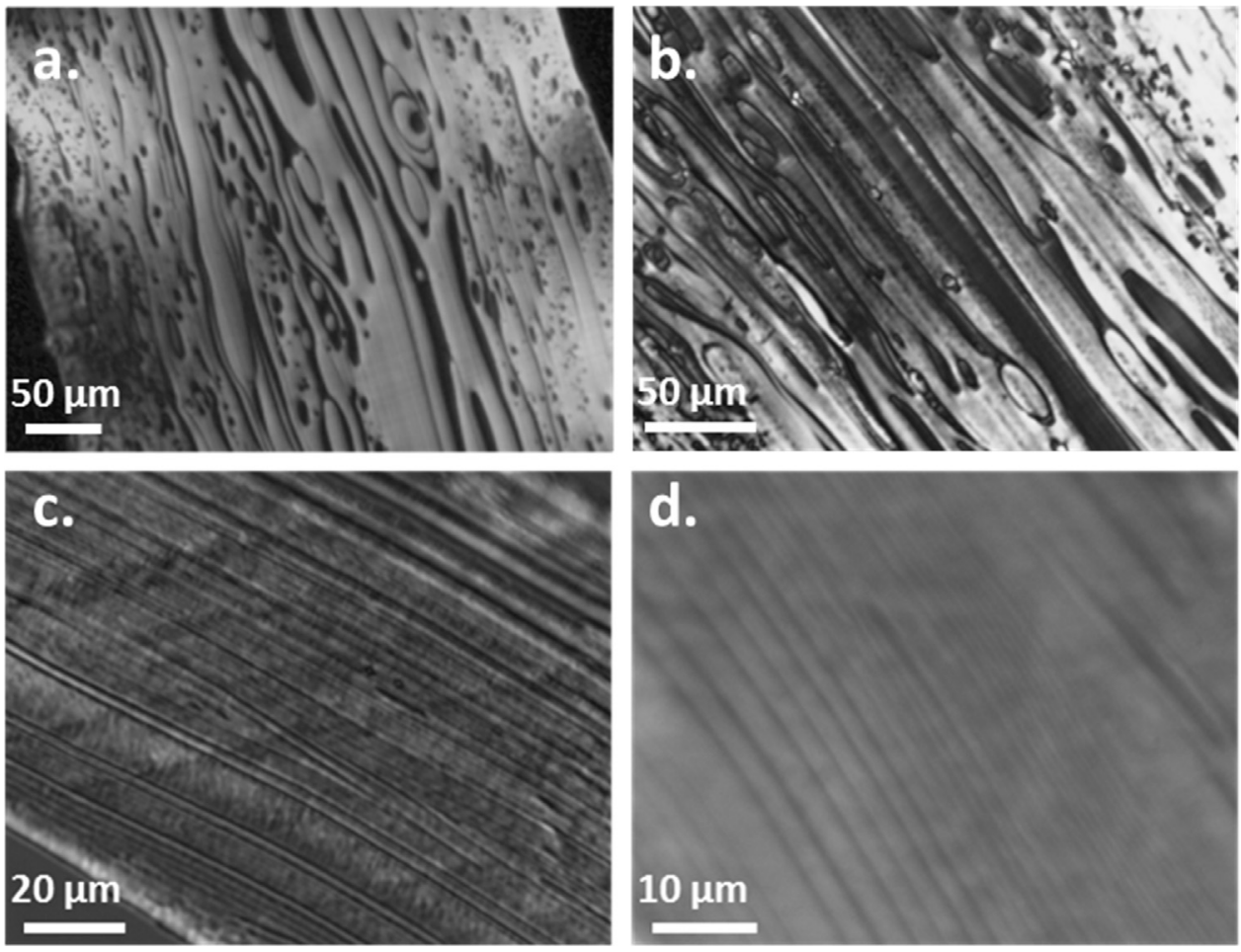

Fig. 2. POM images of the multilayers films (PC in grey, MXD6 in dark): a. and b. (higher magnification) the PC/MXD6-1 (75/25 wt\%) c. and d. (higher magnification) the PC/MXD6-2 $(80 / 20 \mathrm{wt} \%)$.

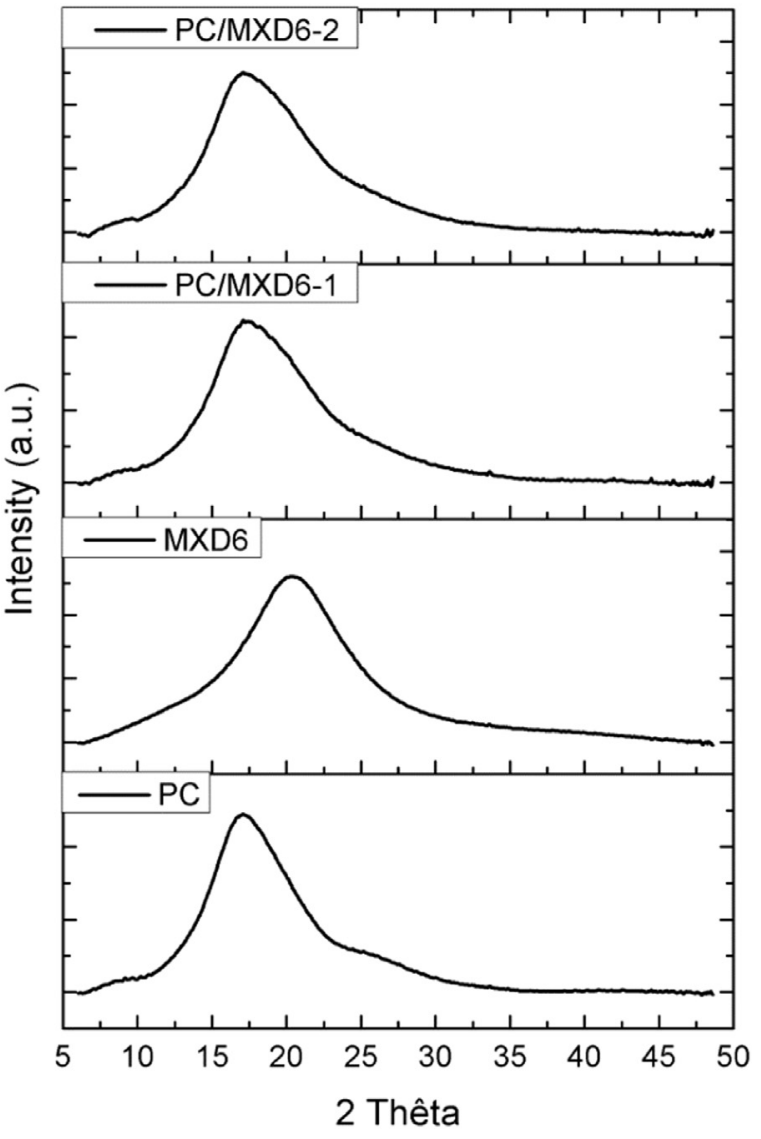

Fig. 3. WAXS diffractograms of the PC monolayer film, the MXD6 monolayer film and the PC/MXD6 multilayer films.
Fig. 4 and the characteristic temperatures (glass transition temperature $\mathrm{Tg}$, melting temperature $\mathrm{Tm}$, crystallization temperatures $\mathrm{Tc}$ ) are gathered in Table 1 . The first heat was considered because it is related to the thermal and structure properties of the material in the same state its barrier properties are characterized. It can be mentioned that the glass transition temperature of $\mathrm{PC}$ being relatively close to the cold crystallization temperature of MXD6 $\left(110-130^{\circ} \mathrm{C}\right)$, MT-DSC experiments were used to separate the two corresponding phenomena occurring in the PC/MXD6 multilayer films. Evenly, tensile tests were performed and characteristic parameters were obtained from the stress-strain curves.

It is worth noting that the thermal and mechanical behaviors (Table 1) of the PC monolayer film are consistent with the literature [36-38]. In addition, the behavior of the PC/PC multilayer film is quite similar to the behavior of the PC monolayer film, except for the degradation temperature, which is found lower. This result could be due to the preparation process, which can slightly reduce the average chain length, as generally observed when using conventional processing technique [39]. Besides, the similar thermal and mechanical values between the PC/PC films and the PC film suggest that the PC amorphous polymer chains were not constrained, indicating the absence of confinement effect of the PC layers within the obtained multilayer structure.

Then the evaluation of the confinement of MXD6 in the multilayer structure was performed from the MXD6 monolayer film and the MXD6/MXD6 multilayer film. The thermal and mechanical characteristics of the MXD6 monolayer film are in good agreement with those reported in the literature $[18,19,28]$, except for the glass transition temperature for which we found two glass transition temperatures, the first one at around $50{ }^{\circ} \mathrm{C}$ and a second one, located more classically at $85^{\circ} \mathrm{C}$. This unexpected low glass transition temperature was probably due to the extrusion processing conditions and certainly to the presence of the residual water within MXD6 pellets and that leads to the plasticization phenomenon. In fact, during the second heat in DSC experiments, only one $\mathrm{Tg}$ was measured at $85^{\circ} \mathrm{C}$, as observed in literature. As for PC and taking into account the error measurements, 

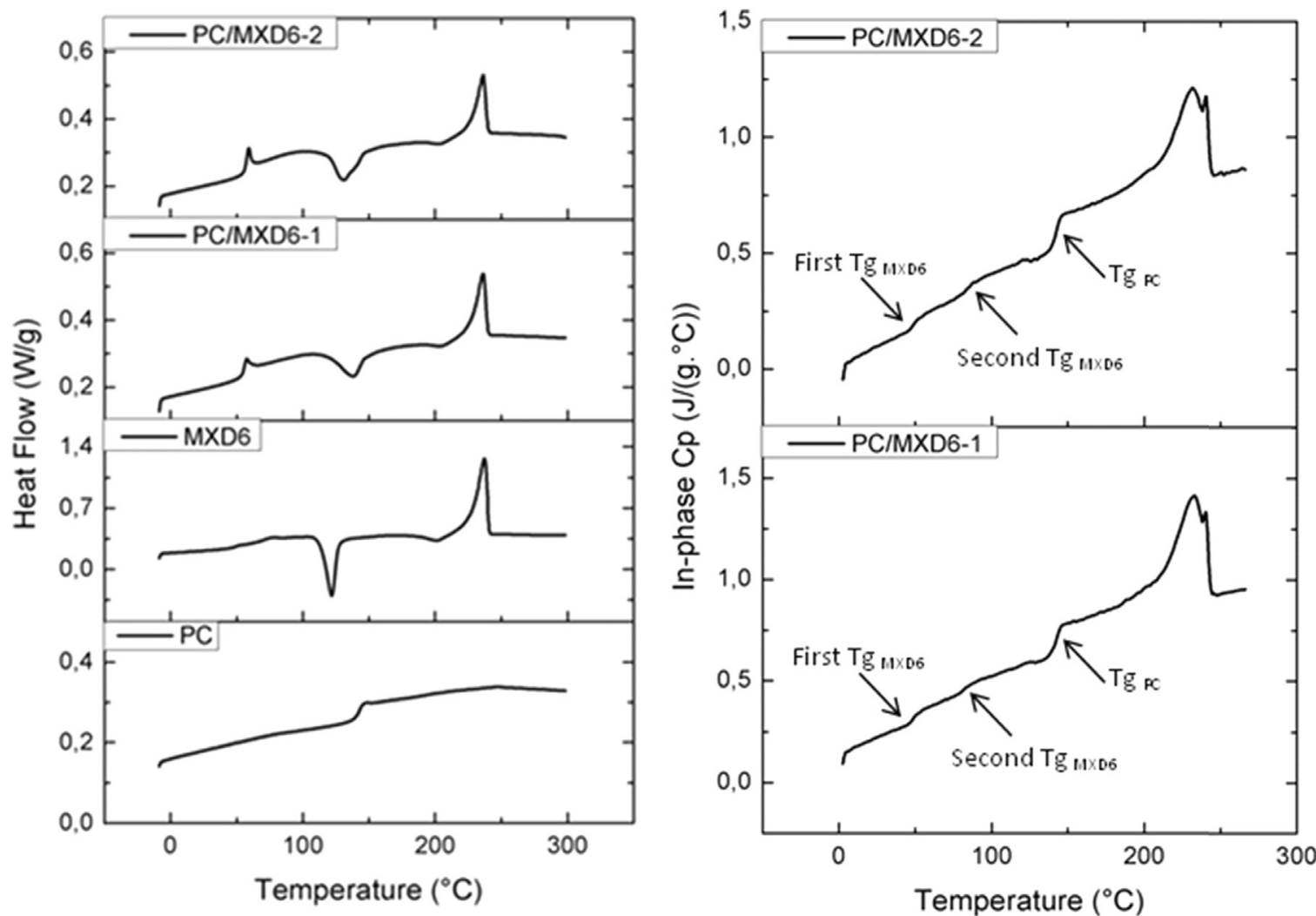

Fig. 4. a) DSC curves of the PC monolayer film, the MXD6 monolayer film and the PC/MXD6 multilayer films, and b) MT-DSC curves of the two PC/MXD6 multilayer films.

Table 1

Thermal and mechanical properties.

\begin{tabular}{|c|c|c|c|c|c|c|c|c|c|c|}
\hline & \multicolumn{7}{|c|}{ Thermal properties $\left({ }^{\circ} \mathrm{C}\right)$} & \multicolumn{3}{|c|}{ Mechanical properties } \\
\hline & $\begin{array}{l}\text { 1st } \operatorname{Tg}_{\mathrm{MXD} 6} \\
\left({ }^{\circ} \mathrm{C}\right)\end{array}$ & $\begin{array}{l}\text { 2nd } \mathrm{Tg}_{\mathrm{MXD} 6} \\
\left({ }^{\circ} \mathrm{C}\right)\end{array}$ & $\operatorname{Tg}_{P C}\left({ }^{\circ} \mathrm{C}\right)$ & $\begin{array}{l}\mathrm{Tc}_{\mathrm{MXD6}} \text { (heat) } \\
\left({ }^{\circ} \mathrm{C}\right)\end{array}$ & $\operatorname{Tm}_{\text {MXD6 }}\left({ }^{\circ} \mathrm{C}\right)$ & $\begin{array}{l}\mathrm{Xc}_{\text {MXD6 }} \\
(\%)\end{array}$ & $\mathrm{T}_{\mathrm{deg}}\left({ }^{\circ} \mathrm{C}\right)$ & $\begin{array}{l}\text { Strength } \\
(\mathrm{MPa})\end{array}$ & $\begin{array}{l}\text { Young's modulus } \\
(\mathrm{MPa})\end{array}$ & Elongation (\%) \\
\hline PC monolayer & - & & 142 & - & - & - & 472 & $60 \pm 10$ & $1530 \pm 170$ & $185 \pm 24$ \\
\hline PC/PC multilayer & - & & 142 & - & - & - & 442 & $69 \pm 5$ & $1575 \pm 65$ & $195 \pm 28$ \\
\hline MXD6 monolayer & 50 & 85 & - & 121 & 236 & 5.5 & 385 & $67 \pm 5$ & $3055 \pm 190$ & $500 \pm 80$ \\
\hline $\begin{array}{l}\text { MXD6/MXD6 } \\
\text { multilayer }\end{array}$ & 54 & 85 & - & 113 & 236 & 2.9 & 385 & $69 \pm 4$ & $3150 \pm 140$ & $560 \pm 60$ \\
\hline $\begin{array}{l}\text { PC/MXD6-1 (75/ } \\
\text { 25) }\end{array}$ & 53 & 85 & 141 & 135 & 236 & 5.5 & 368 & $63 \pm 9$ & $1715 \pm 195$ & $240 \pm 38$ \\
\hline $\begin{array}{l}\text { PC/MXD6-2 (80/ } \\
\text { 20) }\end{array}$ & 50 & 85 & 142 & 131 & 235 & 8.2 & 380 & $58 \pm 7$ & $1485 \pm 95$ & $258 \pm 44$ \\
\hline
\end{tabular}

the MXD6/MXD6 multilayer film presents globally similar mechanical and thermal properties, compared with the MXD6 monolayer film. With our processing conditions, the monolayer MXD6 film as well as the multilayer MXD6-MXD6 and PC-MXD6 films present semi-crystalline MXD6 layers, with the degrees of crystallinity very low, varying from $3 \%$ to $8 \%$ (see Table 1). These results are in accordance with the XRD data indicating a rather amorphous state of the MXD6 monolayer and of the multilayers. The fact that a very low degree of crystallinity is revealed by DSC and not by XRD is due to the shortcomings by both techniques to calculate the degree of crystallinity. By XRD measurements, results have been obtained in one direction at the film surface for a limited thickness. The presence of crystallites at the film surface tends to deflect the X-ray penetration, which made difficult to determine the crystallinity of the entire film sample. In addition, the presence of crystallites, with small sizes, contributes to broadening the XRD peaks, leading to uncertainties. From DSC results, a slight increase of $\mathrm{Tg}$ and a decrease of the degree of crystallinity is obtained for the MXD6/MXD6 multilayer film, compared to the MXD6 monolayer film. This result could be explained by an effect of confinement of
MXD6, which can lead to reduce the chain mobility, and evenly to reduce partially the crystallization phenomenon to be occurred. The inherent properties of MXD6, as obtained when processing the monolayer structure, were maintained in the multilayered structure. The formation of layers within the film did not weaken it and the thermo-mechanical properties are practically constant.

Concerning the PC/MXD6 multilayer films, same characteristic temperatures to the monolayer films were measured, except for the MXD6 crystallization temperature, which increases when in contact with the PC within the multilayer films. The increase of Tc reflects a strain-induced crystallization of the MXD6 by the PC layers. At this stage of discussion, it is worth mentioning that the degree of crystallinity, given in Table 1, originated from semi-crystalline MXD6, the values for both PC/MXD6 multilayer films were calculated by taking into account the weight fraction of MXD6 within the multilayer films. As shown in Table 1, a slight increase of the degree of crystallinity (8.2\% vs $5.5 \%$ ) was measured for the PC/MXD6-2 film, compared to the PC/MXD6-1 film and the MXD6 monolayer film. This increase could be not negligible as the weight fraction of MXD6 in the PC/ 
MXD6 multilayer film is rather low (20\%). It can be explained by the presence of the continuous layers and by the confinement effect of the MXD6 by the PC, contrary to the MXD6/MXD6 multilayer film, for which the reduction of crystallinity is quite surprising. The thermal and mechanical behaviors are found similar for the two multilayer films, except for the Young's modulus, which is higher for the PC/MXD6-1 multilayer film, due to a higher weight fraction of MXD6 (25 wt\% instead of $20 \mathrm{wt} \%)$.

The MT-DSC curves of the PC/MXD6 multilayer films are reported in Fig. 4b. From the MT-DSC curves, a slight change in slope of the Inphase $\mathrm{Cp}$ can be observed at around $85^{\circ} \mathrm{C}$ that was not observed with classical DSC experiments. An enlarged view is also reported to evidence the change in slope, which shows that the two Tg relative respectively to a fraction of dry amorphous phase and a fraction of water-plasticized amorphous phase coexist also in PC-MXD6 multilayer films as in MXD6 single layer film.

\subsection{Barrier properties}

\subsubsection{Transport properties of the PC films}

Barrier properties of the films were examined through gas and water permeation measurements. In addition to water as permeant, three gas molecules $\left(\mathrm{N}_{2}, \mathrm{CO}_{2}\right.$ and $\left.\mathrm{O}_{2}\right)$, differing in diameter and critical temperature, were selected to highlight the change in barrier properties of the multilayer films, compared to the non-structured membranes, the reference films.

The permeability coefficients for the PC monolayer film and PC/PC multilayer films are gathered in Table 2. Similar values between the two films and those of literature [40-44] are obtained, whatever the gas tested. Moreover, as stated by Van Krevelen [45], the well-known tendency in the comparison of gas permeability ranking is observed: $\mathrm{P}_{\mathrm{CO} 2}>\mathrm{P}_{\mathrm{O} 2}>\mathrm{P}_{\mathrm{N} 2}$. This ranking is the result of the double dependence of permeability with diffusivity, which depends mainly on the dynamic diameter of permeants, and with solubility, which depends on the critical temperature of permeants indicative of the ability of a molecule to be condensed in the material. In other words, the more the dynamic diameter is small, the more the diffusion is easier, and as a result the permeability increases. Otherwise, the higher critical temperature of $\mathrm{CO}_{2}\left(31.15^{\circ} \mathrm{C}\right)$, than those of $\mathrm{N}_{2}\left(-146.94{ }^{\circ} \mathrm{C}\right)$ and $\mathrm{O}_{2}\left(-118.56^{\circ} \mathrm{C}\right)$ also explains the greater permeability to carbon dioxide.

Concerning water as permeant, the reduced water permeation fluxes are plotted as a function of the reduced time scale, to overcome the thickness effect, as shown in Fig. 5, and the permeability coefficients are deduced. Same permeability coefficients were obtained between the PC monolayer and the PC/PC multilayer films, but the diffusivity was found slightly lower for the PC/PC multilayer film $\left(1.7 \times 10^{-8} \mathrm{~cm}^{2} \mathrm{~s}^{-1}\right)$, compared to the monolayer film $\left(2.4 \times 10^{-8} \mathrm{~cm}^{2} \mathrm{~s}^{-1}\right)$, reflecting in the time-scale shift of the permeation flux. From results, it can be stated that no noticeable difference exists between the two films, despite the different techniques, which indicates that the confinement of amorphous chains of PC polymer has no effect on permeation properties towards water and gases.

\subsubsection{Transport properties of the MXD6 films}

The values of gas permeability coefficients obtained for the single

Table 2

Gas and liquid water permeation parameters for the PC monolayer and PC/PC multilayer films.

\begin{tabular}{lllll}
\hline & \multicolumn{4}{l}{ Permeability coefficients (Barrer ${ }^{\mathrm{a}}$ ) } \\
\cline { 2 - 5 } & $\mathrm{N}_{2}$ & $\mathrm{O}_{2}$ & $\mathrm{CO}_{2}$ & $\mathrm{H}_{2} \mathrm{O}$ \\
\hline PC monolayer & $0.32 \pm 0.02$ & $1.50 \pm 0.02$ & $7.00 \pm 0.02$ & $1730 \pm 40$ \\
PC/PC multilayer & $0.33 \pm 0.01$ & $1.52 \pm 0.01$ & $7.02 \pm 0.01$ & $1780 \pm 30$ \\
\hline
\end{tabular}

a 1 Barrer $=10^{-10} \mathrm{~cm}_{\text {(STP) }}^{3} \mathrm{~cm} \mathrm{~cm}^{-2} \mathrm{~s}^{-1} \mathrm{cmHg}^{-1}$.

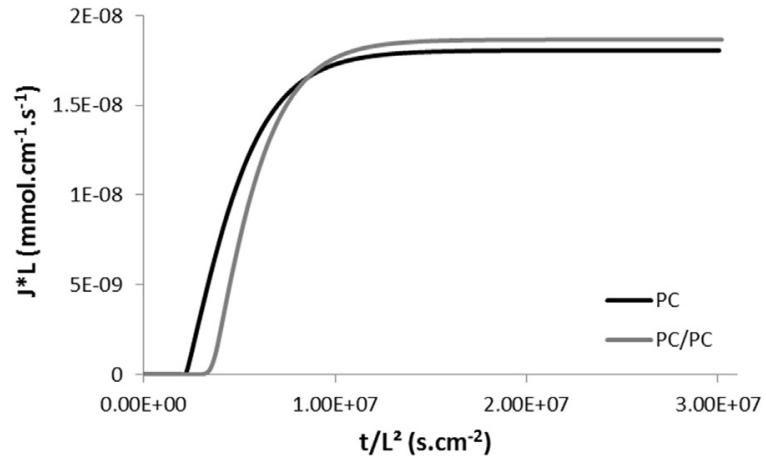

Fig. 5. Reduced water permeation curves for the $\mathrm{PC}$ monolayer and $\mathrm{PC} / \mathrm{PC}$ multilayer films.

layer MXD6 films are: $\mathrm{P}_{\mathrm{CO} 2}=\mathrm{P}_{\mathrm{O} 2}=\mathrm{P}_{\mathrm{N} 2}=0.03$ Barrer (Table 3). These values are strongly higher than those usually given in literature (oxygen permeability 0.003-0.004 Barrer at 0\% RH [18, [46] and 0.008 [47] and than those we already measured to $\mathrm{CO}_{2}$ from another MXD6 (0.001 Barrer) [23]. However, according to literature, it must be considered that the gas permeability of MXD6 is strongly dependent on its structure (crystallinity, orientation) but also on its hydration state.

Indeed, it has been reported that the value of the oxygen permeability coefficient can increase of one order of magnitude with the increase of the relative humidity (for example from $0.1 \mathrm{cc} . \mathrm{mm} / \mathrm{m}^{2} /$ day/ atm at $0 \% \mathrm{RH}$ to $2 \mathrm{cc} . \mathrm{mm} / \mathrm{m}^{2} /$ day $/$ atm at $100 \% \mathrm{RH}$, from data of Mitsubishi). From that, our higher values of permeabilities could be explained by the presence of residual water molecules able to plastify the material (as shown by DSC measurements) and so increase its permeability due to the increase of the free volume. The preliminary drying step of MXD6 is probably not sufficient to remove all water molecules and some of them would be trapped because of strong interactions with amide groups and their confinement in the rigid structure of MXD6. We must also keep in mind that MXD6 has also a rapid water sorption capacity, so that additional water molecules can be sorbed in the MXD6 before measurement. This phenomenon of water retention is even more likely that the thickness of our samples is high $(260 \mu \mathrm{m})$ in comparison with those in literature $(20-80 \mu \mathrm{m})$ $[18,23,46]$. Thus it would have been necessary to force the drying step by increasing the temperature (higher than $100^{\circ} \mathrm{C}$ ) but with the risk of changing the crystalline phase of the material. If the values of the gas permeability coefficients are higher than that expected, they are still low testifying the high barrier level of MXD6 owing to its high rigid structure and the formation of hydrogen bonding between adjacent chains via amide functions, leading strong cohesion between polymer chains. The semi-crystalline structure of MXD6, even at low level of crystallinity in our case, also contribute to the barrier effect, crystals acting as impermeable obstacles to gases. But this low crystallinity degree can also explain the lower gas barrier properties measured on the single layer MXD6 films.

Surprisingly, compared to the MXD6 monolayer film, a decrease of all gas permeability coefficients was observed for the MXD6/MXD6 multilayer film (Table 3) despite a same degree of crystallinity. It seems that the layered structure increase the barrier behavior of the MXD6 polymer.

In the case of water, atypical reduced flux curves were obtained from both the single layer MXD6 films and MXD6/MXD6 multilayer films (Fig. 6). These particular water permeation behaviors are due to the well-known phenomenon called water-induced crystallization. To evidence a crystallization phenomenon induced by water occurring during permeation course, as already observed in previous works [23], two subsequent permeation measurements for the same film were performed to compare water permeation behavior. Before the second measurement within the film, a drying in an oven at $80^{\circ} \mathrm{C}$ during $24 \mathrm{~h}$ 


\begin{tabular}{|c|c|c|c|c|c|c|}
\hline & \multicolumn{6}{|c|}{ Permeability (Barrer) } \\
\hline & \multirow[t]{3}{*}{$\mathrm{N}_{2}$} & \multirow[t]{3}{*}{$\mathrm{O}_{2}$} & \multirow[t]{3}{*}{$\mathrm{CO}_{2}$} & \multicolumn{3}{|l|}{$\mathrm{H}_{2} \mathrm{O}$} \\
\hline & & & & \multicolumn{2}{|l|}{ 1st passage } & \multirow{2}{*}{$\begin{array}{l}\text { 2nd passage } \\
\mathrm{P}_{\text {stat }}\end{array}$} \\
\hline & & & & $\mathrm{P}_{\max }^{*}$ & $\mathrm{P}_{\text {stat }}{ }^{* * *}$ & \\
\hline MXD6 Monolayer & $0.031 \pm 0.002$ & $0.029 \pm 0.001$ & $0.029 \pm 0.002$ & $1110 \pm 30\left(\mathrm{Xc}_{\mathrm{MXD6}}=5.5 \%\right)$ & $640 \pm 50\left(\mathrm{Xc}_{\mathrm{MXD} 6}=30 \%\right)$ & $489 \pm 25$ \\
\hline MXD6/MXD6 Multilayer & $0.020 \pm 0.004$ & $0.015 \pm 0.001$ & $0.015 \pm 0.001$ & $710 \pm 20\left(\mathrm{Xc}_{\mathrm{MXD6}}=2.9 \%\right)$ & $485 \pm 20\left(\mathrm{Xc}_{\mathrm{MXD} 6}=27 \%\right)$ & $347 \pm 90$ \\
\hline
\end{tabular}

${ }^{*} \mathrm{P}_{\max }$ is calculated from the maximum of the flux curve.

${ }^{* * *} \mathrm{P}_{\text {stat }}$ is calculated from the stationary state of the flux curve.

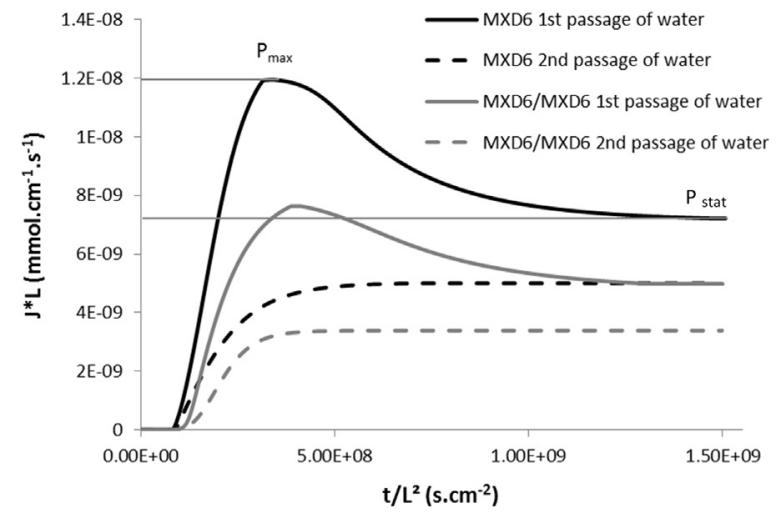

Fig. 6. Reduced water permeation curves for the MXD6 monolayer and MXD6/MXD6 multilayer films.

was applied to the tested film, knowing that this temperature is largely lower than that for which the MXD6 crystallization can occur $\left(130^{\circ} \mathrm{C}\right)$. Fig. 6 presents the thickness-corrected water fluxes, also called reduced water fluxes, as a function of the reduced time. Two curves per film were reported; the first one corresponds to the first measurement (noted first passage of water) applied to the film and the second one corresponds to the second measurement (noted second passage of water) applied to the same film but having overcame the water-induced crystallization during the first measurement. As shown in Fig. 6 and in agreement with a previous work [23], the two curves for a film did not exhibit similar profile and the second curve conforms to a typical permeation curve without dependence of time. The first curve highlights the presence of a maximum water flux (noted $\mathrm{P}_{\max }$ ), from which a decrease as a function of the reduced time is obtained until the stationary flux (noted $\mathrm{P}_{\text {stat }}$ ), corresponding to the steady state of permeation, is reached. This decrease is explained by the occurrence of the crystallization induced by water, with a gradient of water concentration between both sides of the film due to a non-symmetrical crystallization. The degree of crystallinity measured at the end of the first passage of water was significantly increased for both MXD6 films (increase of 24\%), the single layer MXD6 film (from 5.5\% to 30\%) and the MXD6/MXD6 multilayer film (from $2.9 \%$ to 27\%). The reduced water fluxes obtained after the second passage of water show that the steady state is obtained at lower values, meaning that the transfer of water is reduced. Again, this finding is the result of the crystallization phenomenon by water. Indeed, an increase in the delay time of diffusion is measured for the curve corresponding to the second passage of water, due to the larger presence of obstacles to diffusion, which is a higher crystallinity, improving tortuosity effects. The permeability coefficients were determined at the steady state of permeation, i.e. at the longest time of measurement.

From data gathered in Table 3, it can be noted that the water permeability of the MXD6/MXD6 multilayer film decreases, compared to the monolayer film, again due to the multilayered structure, as observed for the three tested gases. It seems that the confinement of the MXD6 polymer chains in lower spaces within the multilayer structure have modify the MXD6 structure at point to increase tortuosity, as revealed by the decrease of the water diffusivity $\left(9.8 \times 10^{-8} \mathrm{~cm}^{2} \mathrm{~s}^{-1}\right.$ for the monolayer film and $6.0 \times 10^{-10} \mathrm{~cm}^{2} \mathrm{~s}^{-1}$ for the multilayer film) related to the time-scale shift of curves. As the MXD6 crystallinity is practically unchanged or slightly reduced between both MXD6 films (30\% vs 27\%), an orientation of crystals in the confined MXD6 layers is expected to be at the origin of the increase of the diffusion pathways owing to the increase of tortuosity. In addition, considering that polymer chains within the amorphous phase are constrained by confinement effect due to the forced assembly induced by the coextrusion process, the reduction of the chain mobility should lead to decrease the diffusivity of water molecules.

Because the degree of crystallinity of the MXD6 film was largely increased after the first water passage (Table 3) due to the waterinduced crystallization phenomenon, the permeability to water after the second measurement was reduced (Table 3). During the second passage of water, for both films (monolayer and multilayer films), it can be seen now the typical permeation curve, without water induced crystallization, meaning that the transport properties of both films are now stabilized.

Also from water permeation results, it can be noted that barrier effect due to the confinement of MXD6 crystals within the multilayered film is assumed to be equivalent to an increase of $\sim 25 \%$ of crystallinity, if we compare the permeability coefficients obtained after the second passage of water through the MXD6 monolayer film and after the first passage of water through the MXD6/MXD6 multilayer film. It is interesting to see that due to the confinement of MXD6 in multilayer form, the gas and water barrier properties are strongly increased. However, despite this increase in moisture resistance, the waterinduced crystallization stills occurs in the MXD6/MXD6 multilayer film, leading to similar increase of crystallinity (Table 3).

\subsubsection{Transport properties of the PC/MXD6 multilayer films}

Concerning the gas permeation, the values of the permeability coefficients (Table 4) for the two PC/MXD6 films are slightly lower for the first series compared to the second one as it contains more MXD6 ( $25 \%$ vs $20 \%$ ). However, the gas permeability ranking complies with the works of Van Krevelen [45] since the $\mathrm{P}_{\mathrm{CO} 2}>\mathrm{P}_{\mathrm{O} 2}>\mathrm{P}_{\mathrm{N} 2}$ tendency is still obtained.

To demonstrate the possible effect of the confinement effect of the MDX6 polymer, resulting to the processing of the multilayer structure, on the gas barrier properties, permeability values were calculated using the Maxwell model (Eq. (5)) and the series model (Eq. (6)), taken into account the volume fraction $\varphi$ and the experimental permeability coefficient $P$ of each polymer, and then confronted with the experimental values. As it can be seen in Table 4, a significant difference is observed between the experimental and calculated permeability values for the two films. In comparison with the values calculated with Maxwell equation, the experimental values are widely inferiors. Also, 


\begin{tabular}{|c|c|c|c|c|c|}
\hline & \multicolumn{5}{|c|}{ Permeability (Barrer) } \\
\hline & \multirow[t]{2}{*}{$\mathrm{N}_{2}$} & \multirow[t]{2}{*}{$\mathrm{O}_{2}$} & \multirow[t]{2}{*}{$\mathrm{CO}_{2}$} & \multicolumn{2}{|l|}{$\mathrm{H}_{2} \mathrm{O}$} \\
\hline & & & & First passage & Second passage \\
\hline PC/MXD6-1 (75/25) & $0.044 \pm 0.004$ & $0.055 \pm 0.003$ & $0.112 \pm 0.003$ & $1450 \pm 200(\mathrm{Xc}=5.5 \%)$ & $1350 \pm 90(\mathrm{Xc}=10.2 \%)$ \\
\hline Calculated permeability (Maxwell model, Eq.(5)) & 0.228 & 1.022 & 4.721 & 1413 & / \\
\hline Calculated permeability (series model, Eq.(6)) & 0.097 & 0.112 & 0.117 & 1220 & / \\
\hline PC/MXD6-2 (80/20) & $0.054 \pm 0.001$ & $0.059 \pm 0.003$ & $0.153 \pm 0.007$ & $1225 \pm 250(\mathrm{Xc}=8.2 \%)$ & $1210 \pm 110(\mathrm{Xc}=14.6 \%)$ \\
\hline Calculated permeability (Maxwell model, Eq.(5)) & 0.245 & 1.107 & 5.128 & 1472 & / \\
\hline Calculated permeability (series model, Eq.(6)) & 0.113 & 0.137 & 0.145 & 1295 & / \\
\hline
\end{tabular}

the experimental values are found significantly lower to those calculated with the series model equation for $\mathrm{N}_{2}$ and $\mathrm{O}_{2}$ gases while for $\mathrm{CO}_{2}$ gas, no noticeable difference is observed. In fact, for $\mathrm{CO}_{2}$ gas, the ratio of the permeability coefficients of the PC over the MXD6 is so high $(P \mathrm{PC} / P \mathrm{MXD6}=230)$ that the effect due to confined MXD6 layers within the multilayer structure becomes negligible. These permeation results show clearly that the elaborated systems have a structure closer to a multilayer than to a classical binary system.

For water permeation, the PC/MXD6-2 film globally present a lower value of the permeability coefficient compared to that of the PC/ MXD6-1 film, although the mass fraction of MXD6 is lower. This result can be attributed to the fact that irregular, but continuous MXD6 layers were formed within the PC/MXD6-2 film. Moreover, the experimental value is close to the calculated one for the PC/MXD6-2 film, whereas the experimental value is found higher for the PC/MXD6-1 film. This finding can be explained by the slight gap in crystallinity of MXD6 (series $1: 5.5 \%$ and series $2: 8.2 \%$ ) between the two films.

As above-observed with the MXD6 films, when applying two subsequent passages of water through the tested film, the permeability and diffusivity coefficients were slightly decreased for both PC/MXD6 multilayer films after the second water permeation measurement (Fig. 7). This result is again related to the water-induced crystallization of MXD6 occurring during the first passage of water, which slows down the water transfer during the second passage by an increase in crystallinity. This increase of crystallinity was confirmed by DSC as the degree of crystallinity was practically two times higher after the first passage of water.

Assuming that only the semi-crystalline structure of the MXD6 can be at the origin of the confinement effect induced by forced assembly during multilayer structure processing, it became interesting to evaluate the improvement of the barrier properties of MXD6 layers by recalculating the permeability of MXD6 within the multilayer film. For this, from the experimental permeability coefficient obtained for the PC film and those for the multilayer films, and also taken into account the volume fractions of PC and MXD6 within the multilayer structures, the

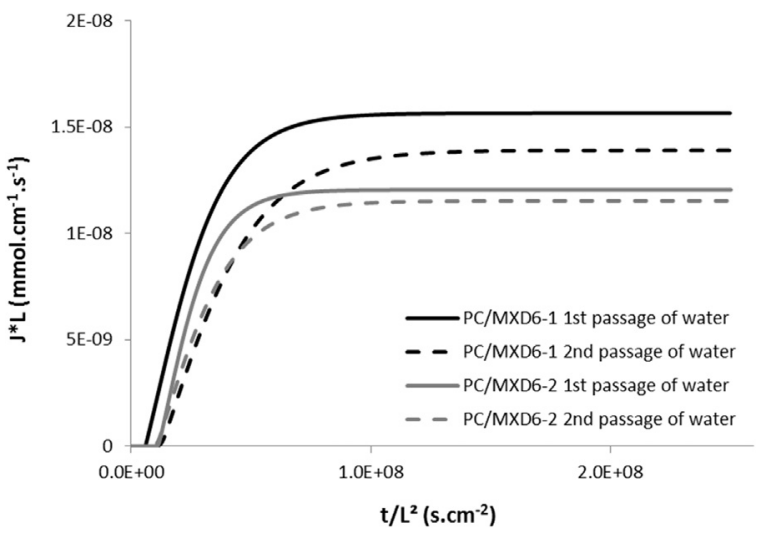

Fig. 7. Reduced water permeation curves for the PC/MXD6 multilayer films.
Table 5

Calculated permeability coefficients of MXD6 within the PC/MXD6 films and the corresponding BIF factor.

\begin{tabular}{lllll}
\hline & \multicolumn{3}{l}{ Permeability (Barrer) } & \\
\cline { 2 - 5 } & $\mathrm{N}_{2}$ & $\mathrm{O}_{2}$ & $\mathrm{CO}_{2}$ & $\mathrm{H}_{2} \mathrm{O}$ \\
\hline MXD6 monolayer film & 0.031 & 0.029 & 0.029 & 640 \\
Calculated $P_{\text {MXD6 in PC/MXD6-1 }}$ & 0.012 & 0.014 & 0.028 & 967 \\
BIF (\%) & 61 & 57 & 4 & $<0$ \\
Calculated $P_{\text {MXD6 }}$ in PC/MXD6-2 & 0.012 & 0.012 & 0.031 & 557 \\
BIF (\%) & 61 & 59 & 0 & 13 \\
\hline
\end{tabular}

permeability coefficient of MXD6 was re-calculated as follows:

$P_{\mathrm{MXD} 6}=\frac{\varphi_{\mathrm{MXD} 6}}{\frac{1}{P_{\mathrm{Film}}}-\frac{\varphi_{\mathrm{PC}}}{P_{\mathrm{PC}}}}$

The new calculated permeability values were compared with the experimental values (Table 5) to highlight how the confinement in a layered structure can influence the barrier effect and that can be quantified through the Barrier Improvement Factor (BIF factor, expressed in \%). This useful metric to normalize and compare permeability results can be determined as the difference between the permeability in the MXD6 monolayer film permeability with the permeability in MXD6 layers within the PC/MXD6 multilayer film divided by the permeability of the MXD6 monolayer film. For $\mathrm{N}_{2}$ and $\mathrm{O}_{2}$ gases, both PC/MXD6 films were characterized by a similar BIF around $60 \%$, indicating that barrier performances were largely improved due to the tortuosity induced by the layered structure. For $\mathrm{CO}_{2}$ gas, the improvement factor is close to 0 , meaning that no effect on permeability was obtained. This result can be explained by the high solubility of $\mathrm{CO}_{2}$ gas resulting to both its low diameter, the lowest value considering the two other gases tested, and its high critical temperature, the highest value considering the two other gas temperatures. In this case, the permeability of $\mathrm{CO}_{2}$ was not improved by the spatial organization in the layered films. Regarding water as permeant, the BIF for the PC/MXD6-2 film was determined equal to $13 \%$. Again, the BIF factor reflects an enhanced permeability of water, which proves the positive influence of the presence of continuous MXD6 layers on barrier properties compared to a film prepared from a classical polymer blending. In the case of the PC/MXD6-1 film, the BIF was found negative, meaning that the water transfer is not reduced but inversely is increased due certainly to the non-homogeneous structure characterized by non-continuous layers and by stretched nodules that could create diffusion pathways for these plasticizing molecules.

From all permeation data, it results that the confinement of the semi-crystalline MXD6 in multilayer form by using the amorphous glassy PC as confiner layer leads to highly increase gas barrier properties of MXD6. It was also shown that water barrier properties are increased when the multilayer structure is well defined with continuous layer and relatively homogeneous thickness (PC/MXD6-2 film). In that case, the degree of crystallinity was accordingly increased. 


\section{Conclusion}

By applying the forced assembly of the layer-multiplying coextrusion process, immiscible polymers can be together combined in unique film stack with ultrathin layers. Ultrathin layer polymer membranes present reduced dimensions, which confine polymer crystallization to sizes assumed to be of the order of magnitude close to individual lamellar crystals. However, in the present work, the difficulty of processing a homogeneous multilayer film with continuous and regular ultrathin layers, composed of semi-crystalline MXD6 polymer, can be partly explained by a poor compatibility between the two polymers MXD6 and PC, or polymer-polymer affinity at the interface between adjoining layers, but also resulted to experimental processing conditions through the temperature applied during the coextrusion process. Therefore, it has been showed that it is possible to create multilayer structure of MXD6 in MXD6 that shows that the co-extrusion multiplying process permits to generate multilayer structure also with miscible polymers. Indeed, to develop a confined environment at a nano-scale for polymer crystallization, it is assumed that the semicrystalline polymer has to be sandwiched between two layers of a rigid amorphous polymer presenting a high melting temperature. However, in our case, the confined environment is provided by the amorphous PC polymer with a processing temperature around $230^{\circ} \mathrm{C}$, whereas the melting temperature of MXD6 is around $250{ }^{\circ} \mathrm{C}$. This slight difference, in addition to the processing effect and the lack of compatibility, can mainly explain the non-homogenous organization of MXD6 layers within the PC/MXD6 multilayer films.

Independently to form ultrathin layers within a multilayer film, one of the most promising effect mediated by the spatial confinement occurring in two dimensions concerns the possibility to preferentially orientate polymer crystals parallel to the layer. This kind of orientation is a key factor in the field of barrier applications to specifically improve the resistance to diffusive species. But from DSC analyses, it can be deduced that MXD6 was mainly in its amorphous state in monolayer as well as in multilayer films. The geometrical confinement does not lead to a sufficient increase of the crystallization rate permitting to hope crystalline orientation. From permeation data, it clearly appears that the transport properties of the MXD6 are improved in multilayer form, either of pure MXD6 (MXD6/MXD6) or associated with PC (PC/ MXD6), compared to the MXD6 monolayer film. The permeability coefficient is reduced, as that the initial permeability was already low. Unlike gas molecules, the water-induced crystallization of MXD6 within MXD6/MXD6 film is highlighted due to achieving permeation profile with maximum threshold during water permeation measurements. This implies a significant increase in crystallinity and accordingly a reduction in water permeability. This phenomenon is not occurred in the second measurement because of the increased degree of crystallinity which has reached a maximum at the steady state of the first permeation. Regarding the PC/MXD6 films, this phenomenon is prevented due to the protective role of the outer PC layers, irrespective of the layer continuity within the multilayer films. Again, low permeability coefficients are measured, despite the large fraction of the amorphous PC polymer. The mobility of polymer chains is reduced in amorphous constrained zones. The barrier improvement of the MXD6 layers was evaluated by applying the well-known series model used to re-calculate the MXD6 permeability from the experimental data. Through the BIF factor, irrespective of permeants, the films' performances are pointed out. The correlation between the permeation properties and the morphology provides evidence that the 2-D confinement induced by the multilayer process, and as a result the improvement of barrier performances. The coextrusion process with the possibility to multiply ultrathin layers is an innovative system to create a direct polymer assembly presenting new morphology with hundreds until thousands of alternating layers of polymers and can exhibit properties multiplied many-fold by the layer number in the assembly.

\section{Acknowledgment}

The authors thank the GRR Crunch (Grant No. EOTP No 427341) (supported by Upper Normandy region, France) for the financial support of the PhD fellowship of T. Messin.

\section{References}

[1] J. Dooley, H. Tung, Coextrusion, Encyclopedia of Polymer Science and Technology, John Wiley \& Sons, Inc., 2002.

[2] K. Lamnawar, H. Zhang, A. Maazouz, Coextrusion of Multilayer Structures, Interfacial Phenomena, Encyclopedia of Polymer Science and Technology, John Wiley \& Sons, Inc., 2002.

[3] M. Ponting, A. Hiltner, E. Baer, Polymer nanostructures by forced assembly: process, structure, and properties, Macromol. Symp. 294 (2010) 19-32.

[4] W.J. Schrenk, Method for Multilayer Coextrusion, 1973, Google Patents.

[5] W.J. Schrenk, N.L. Bradley, T. Alfrey Jr., H. Maack, Interfacial flow instability in multilayer coextrusion, Polym. Eng. Sci. 18 (1978) 620-623.

[6] T. Kazmierczak, H. Song, A. Hiltner, E. Baer, Polymeric one-dimensional photonic crystals by continuous coextrusion, Macromol. Rapid Commun. 28 (2007) 2210-2216.

[7] T. Ebeling, A. Hiltner, E. Baer, Delamination failure mechanisms in microlayers of polycarbonate and poly (styrene-co-acrylonitrile), J. Appl. Polym. Sci. 68 (1998) $793-805$.

[8] J. Kerns, A. Hsieh, A. Hiltner, E. Baer, Mechanical behavior of polymer microlayers, Macromol. Symp. 147 (1999) 15-25.

[9] Y. Lin, A. Hiltner, E. Baer, A new method for achieving nanoscale reinforcement of biaxially oriented polypropylene film, Polymer 51 (2010) 4218-4224.

[10] H. Wang, J.K. Keum, A. Hiltner, E. Baer, B. Freeman, A. Rozanski, A. Galeski, Confined crystallization of polyethylene oxide in nanolayer assemblies, Science 323 (2009) 757-760.

[11] G. Zhang, P.C. Lee, S. Jenkins, J. Dooley, E. Baer, The effect of confined spherulite morphology of high-density polyethylene and polypropylene on their gas barrier properties in multilayered film systems, Polymer 55 (2014) 4521-4530.

[12] J.M. Carr, D.S. Langhe, M.T. Ponting, A. Hiltner, E. Baer, Confined crystallization in polymer nanolayered films: a review, J. Mater. Res. 27 (2012) 1326-1350.

[13] H.P. Wang, J.K. Keum, A. Hiltner, E. Baer, Crystallization kinetics of poly(ethylene oxide) in confined nanolayers, Macromolecules 43 (2010) 3359-3364.

[14] M. Ponting, Y. Lin, J.K. Keum, A. Hiltner, E. Baer, Effect of substrate on the isothermal crystallization kinetics of confined poly ( $\varepsilon$-caprolactone) nanolayers, Macromolecules 43 (2010) 8619-8627.

[15] M. Mackey, L. Flandin, A. Hiltner, E. Baer, Confined crystallization of PVDF and a PVDF-TFE copolymer in nanolayered films, J. Polym. Sci. Part B Polym. Phys. 49 (2011) 1750-1761.

[16] K. Arabeche, L. Delbreilh, R. Adhikari, G.H. Michler, A. Hiltner, E. Baer, J.M. Saiter, Study of the cooperativity at the glass transition temperature in PC/ PMMA multilayered films: influence of thickness reduction from macro-to nanoscale, Polymer 53 (2012) 1355-1361.

[17] A. Ammala, J.M. Lagaron (Ed.)Multifunctional and Nanoreinforced Polymers for Food Packaging, Woodhead Publishing in Materials, Oxford, Cambridge, Philadelphia, New Delhi, 2011.

[18] Y.S. Hu, V. Prattipati, S. Mehta, D.A. Schiraldi, A. Hiltner, E. Baer, Improving gas barrier of PET by blending with aromatic polyamides, Polymer 48 (2005) $2685-2698$.

[19] B. Ben Doudou, E. Dargent, J. Grenet, Relationship between draw ratio and straininduced crystallinity in uniaxially hot-drawn PET MXD6 films, J. Plast. Film Sheeting 21 (2005) 233-251.

[20] B. Ben Doudou, E. Dargent, J. Grenet, Crystallization and melting behaviour of poly (m-xylene adipamide), J. Therm. Anal. Calorim. 85 (2006) 409-415.

[21] B. Ben Doudou, E. Dargent, S. Marais, J. Grenet, Y. Hirata, Barrier properties and microstructure modifications induced by liquid water for a semiaromatic polyamide, J. Polym. Sci. Part B Polym. Phys. 43 (2005) 2604-2616.

[22] Y.S. Hu, S. Mehta, D.A. Schiraldi, A. Hiltner, E. Baer, Effect of water sorption on oxygen-barrier properties of aromatic polyamides, J. Polym. Sci. Part B Polym. Phys. 43 (2005) 1365-1381.

[23] C.L. Buquet, B. Ben Doudou, C. Chappey, E. Dargent, S. Marais, Permeation properties of poly(m-xylene adipamide) membranes, J. Phys. Chem. B 113 (11) (2009) 3445-3452.

[24] C. Sollogoub, A. Grandmontagne, A. Guinault, Instabilities in a layer-multiplying device, in: Proceedings of the International Conference on Advances in Materials and Processing Technologies (AMPT2010), 2011, AIP Publishing.

[25] Y. Zhu, A. Bironeau, F. Restagno, C. Sollogoub, G. Miquelard-Garnier, Kinetics of thin polymer film rupture: model experiments for a better understanding of layer breakups in the multilayer coextrusion process, Polymer 90 (2016) 156-164.

[26] M. Boufarguine, A. Guinault, G. Miquelard-Garnier, C. Sollogoub, PLA/PHBV films with improved mechanical and gas barrier properties, Macromol. Mater. Eng. 298 (2003) 1065-1073.

[27] X. Li, G.B. McKenna, G. Miquelard-Garnier, A. Guinault, C. Sollogoub, G. Regnier, A. Rozanski, Forced assembly by multilayer coextrusion to create oriented grapheme reinforced polymer nanocomposites, Polymer 55 (2014) 248-257.

[28] M. Fereydoon, S.H. Tabatabaei, A. Ajji, Rheological, crystal structure, barrier, and mechanical properties of PA6 and MXD6 nanocomposite films, Polym. Eng. Sci. (2014) 2618-2631. 
[29] C. Joly, D. Le Cerf, C. Chappey, D. Langevin, G. Muller, Residual solvent effect on the permeation properties of fluorinated polyimide films, Sep. Purif. Technol. 16 (1999) 47-54.

[30] L. Nielsen, Predicting the Properties of Mixtures, Marcel Dekker Inc., New York, 1978.

[31] Z. Sadeghi, M. Omidkhah, M.E. Masoumi, R. Abedini, Modification of existing permeation models of mixed matrix membranes filled with porous particles for gas separation, Can. J. Chem. Eng. 94 (2016) 547-555.

[32] Z. Sadeghi, M. Omidkhah, M.E. Masoumi, New permeation model for mixed matrix membrane with porous particles, Int. J. Chem. Eng. Appl. 6 (5) (2015) 325-330.

[33] M. Gupta, Y. Lin, T. Deans, E. Baer, A. Hiltner, D.A. Schiraldi, Structure and gas barrier properties of poly(propylene-graft-maleic anhydride)/phosphate glass composites prepared by microlayer coextrusion, Macromolecules 43 (2010) 4230-4239.

[34] V. Prattipati, Y.S. Hu, S. Bandi, D.A. Schiraldi, A. Hiltner, E. Baer, S. Mehta, Effect of compatibilization on the oxygen-barrier properties of poly(ethylene terephthalate)/poly(m-xylylene adipamide) blends, J. Appl. Polym. Sci. 97 (2005) 1361-1370.

[35] H. Wang, J.K. Keum, A. Hiltner, E. Baer, Confined crystallization of PEO in nanolayered films impacting structure and oxygen permeability, Macromolecules 42 (2009) 7055-7066.

[36] J. Feng, J. Hao, J. Du, R. Yang, Effects of organoclay modifiers on the flammability, thermal and mechanical properties of polycarbonate nanocomposites filled with a phosphate and organoclays, Polym. Degrad. Stab. 97 (2012) 108-117.

[37] G. Weibin, H. Shimin, Y. Minjiao, J. Long, D. Yi, The effects of hydrothermal aging on properties and structure of bisphenol A polycarbonate, Polym. Degrad. Stab. 94
(2009) $13-17$.

[38] Y. Zhou, Y. Dan, L. Jiang, G. Li, The effect of crystallization on hydrolytic stability of polycarbonate, Polym. Degrad. Stab. 98 (2013) 1465-1472.

[39] S.V. Canevarolo, Chain scission distribution function for polypropylene degradation during multiple extrusions, Polym. Degrad. Stab. 709 (2000) 71-76.

[40] H. Kim, C.W. Macosko, Processing-property relationships of polycarbonate/graphene composites, Polymer 50 (2009) 3797-3809.

[41] R.Y.F. Liu, A.P. Ranade, H.P. Wang, T.E. Bernal-Lara, A. Hiltner, E. Baer, Forced assembly of polymer nanolayers thinner than the interphase, Macromolecules 38 (2005) 10721-10727.

[42] S.I. Moon, C.W. Extrand, Water vapor permeation resistance of polycarbonate at various temperatures, Ind. Eng. Chem. Res. 48 (2009) 8961-8965.

[43] S.I. Moon, L. Monson, C.W. Extrand, Outgassing of oxygen from polycarbonate, ACS Appl. Mater. Interfaces 1 (2009) 1539-1543.

[44] C. Shih-Hsiung, L. Juin-Yih, R. Ruoh-Chyu, A.W. Andy, Gas sorption and transport properties of the membrane from polycarbonate/CoIII acetylacetonate blend, J. Membr. Sci. 123 (1997) 197-205.

[45] D.W. Van Krevelen, Properties of Polymers, 3rd ed., Elsevier, Amsterdam/Oxford, 1990.

[46] C. Thellen, S. Schirmer, J.A. Ratto, B. Finnigan, D. Schmidt, Co-extrusion of multilayer poly(m-xylylene adipimide) nanocomposite films for high oxygen barrier packaging applications, J. Membr. Sci. 340 (2009) 45-51.

[47] Y. Wang, S.A. Jabarin, Novel preparation method for enhancing nanoparticule dispersion and barrier properties of poly(ethylene terephthalate) and poly(mxylylene adipamide), J. Appl. Polym. Sci. 129 (2013) 1455-1465. 